\title{
Development and Usability Test of Hangeul Font Registration System
}

\author{
Eun-Joo Sin ${ }^{1}$, Ki-Deok Park ${ }^{2}$, Soon-Bum Lim ${ }^{3}$ \\ Dept. of IT-Engineering Sookmyung Women's University, \\ Cheongpa-ro 47-gil 100, Yongsan-gu, Seoul, 140-742, Korea ${ }^{1,3}$ \\ Mobile Communication $R \& D$ Center, \\ HanYang Information \& Communications Co \\ Banbae-ro 114-gil 4F, Seocho-gu, Seoul, Korea ${ }^{2}$ \\ kiki75@gmail.com ${ }^{1}$,kdpark@hanyang.co.kr ${ }^{2}$,sblim@sookmyung.ac.kr ${ }^{3}$
}

\begin{abstract}
This paper describes development and usability evaluation of Korea's Hangeul font registration system. As the use of fonts increases, various fonts are produced. However, finding the fonts you want is not an easy task. Therefore, we have developed a system that can integrate existing fonts and search for desired fonts through the Korean font registration system. In addition, we evaluated the possibility and improvement plan of the system by evaluating whether the system can be actually useful to users.
\end{abstract}

Keywords: Hangeul, Korean alphabet, font registration system, usability test

\section{Introduction}

Contrary to the past, when has been mainly used in printed matter, modern characters have a role of communication in various devices. It becomes necessary to transmit not only the contextual literacy but also the sensibility according to the design factors. These needs are being developed in various fonts. However, it is not easy to find a font that you need among many fonts. It is difficult to check all the fonts provided by each developer and find the fonts of non-specialists made for sharing cannot be easily found. At present, in order to find a desired font, various routes such as a search site and a font-related site, must be checked[1,2]. This effort also limits the ability of searching fonts.

Finding suitable fonts for various situations and media is very important and is a problem that is necessary for modern people who live as prosumers. Consequently, we developed a hangeul font registration system that can convert all existing fonts into a DB and search them. 'Hangeul maeul'[3], is the first case of Korean font registration system, which enables not only experts' fonts but also the fonts of non-specialists to be registered and searched. In addition, it also provides an editor that simplifies the difficult and vast process of creating Korean fonts so that anyone can create and share fonts.

Even though the hangeul font registration system is the most demanding system, if it is not usable, it will be ignored by users. Therefore, we test the usability of the developed hangeul font registration system for font registration and retrieval, and confirmed the future improvement in this paper. Usability test is not a one-off event, thus we will improve the system through repeated tests and improvements.

\section{Related Works}

In order to retrieve Korean fonts, it is necessary to have the shape and characteristics of fonts that users can easily distinguish. The Telecommunications Technology Association

3 Corresponding Author: Soon-Bum Lim 
of Korea standardizes the design-based classification for the Korean font registration system[4]. Compared to English or Japanese, which have international standards[5], Hangeul font classification has only recently been developed[6,7,8] and has been produced and used without any classification standard for different developers. The font classification standard of this standard is summarized by using the visual characteristics of the stroke and the writing instrument features used[9]. Table 1 is a visual classification table of Korean fonts.

Table 1. Visual Classification Table of Korean Fonts

\begin{tabular}{|c|c|c|c|}
\hline $\begin{array}{l}\text { large scale } \\
\text { classification }\end{array}$ & $\begin{array}{l}\text { medium scale } \\
\text { classification }\end{array}$ & $\begin{array}{l}\text { small scale } \\
\text { classification }\end{array}$ & Samples \\
\hline \multirow{6}{*}{ Printing } & \multirow{3}{*}{ Serif } & Monanburiche & 훈민정음 훈민정음 \\
\hline & & Dunggeunburiche & 훈민정음 훈민정음 \\
\hline & & Eungyongburiche & 훈민정음 훈민정음 \\
\hline & \multirow{3}{*}{ San Serif } & Monanminburiche & 훈민정음 훈민정음 \\
\hline & & Dunggeunminburiche & 훈민정음 운민정음 \\
\hline & & Eungyongminburiche & 군영 문민정음 \\
\hline \multirow{6}{*}{ Script } & \multirow{3}{*}{ Brush } & Jeongjache & 훈 민 정음 훈민청음 \\
\hline & & Heullimche & 곤 밀 헝음 훈민겅음 \\
\hline & & Goseoche & 훈민정음 \\
\hline & \multirow{2}{*}{ Pen } & Jeongjache & 훈민정음 훈민정음 \\
\hline & & Heullimche & 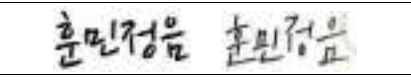 \\
\hline & Other Scripts & 훈민정음 훈 & 기음 훈인정음 \\
\hline \multirow{2}{*}{ Inscriptional } & Wood Plate & 흔민징음 훈 & 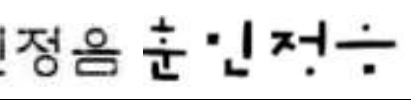 \\
\hline & $\begin{array}{l}\text { Other } \\
\text { Inscriptional }\end{array}$ & 훈민정음 홓 & 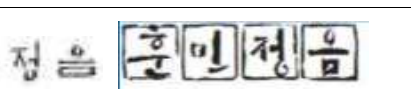 \\
\hline \multirow{4}{*}{ Ornament } & Graphic & 후ㄴㅣㅣ정음 훈. & 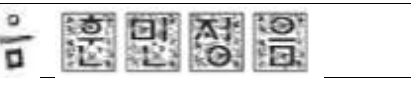 \\
\hline & Pattern & 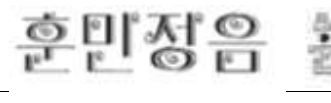 & 2! - \\
\hline & Modified & & \\
\hline & Texture & 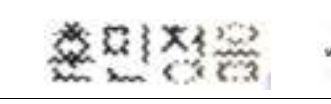 & $\frac{1}{2} \lambda-\frac{1}{2} \div \frac{0}{0}$ \\
\hline Others & \multicolumn{3}{|c|}{$\begin{array}{l}\text { As the design area of Hangeul font is expanded, this is an area for fonts that } \\
\text { do not belong to the existing design classification standard. }\end{array}$} \\
\hline
\end{tabular}


Visual classification standards were developed by Hangeul font development experts, international and domestic standard experts, and of publishing-related academic and industry experts. Moreover, since it is the first systematic classification of Hangeul font, it is expected to shorten the retrieval and registration time in terms of the user side and development provider side. The system of this paper also developed a registration system based on this classification.

\section{Hangeul font Registration System}

The ' Hangeul maeul ' system is the first case of Hangeul font registration system that aims to register and search all existing Hangeul fonts. Since the development (2016.5) and now (2017.1), 1,526 fonts have been registered and searched, it is expected to gradually expand in the future.
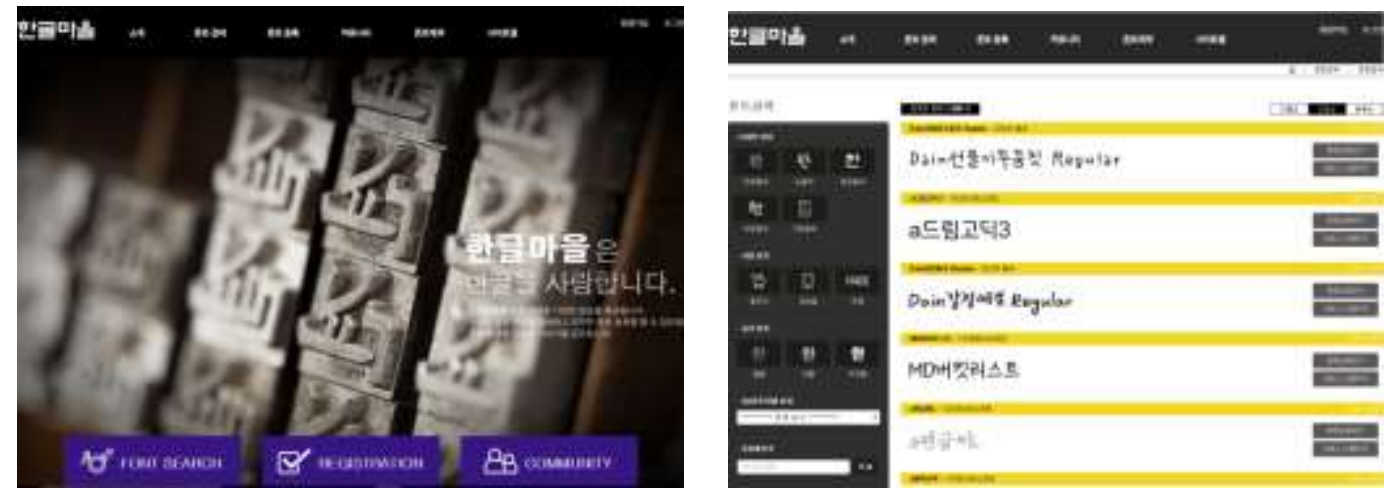

Figure 1. Hangeul maeul (http://www.koreafont.com)

The registered fonts are displayed on the 'Hangeul maeul' site, and provide font search result information to domestic/foreign companies, designers, and government agencies that require fonts. The registration process, which enables you to search by design, code specification, support format, copyright holder, license, purchase information, etc., allows to search the font quickly and conveniently according to the purpose of use. This can advance the Korean font industry by preventing copyright and licensing problems and allowing the user to purchase the desired Hangeul font.

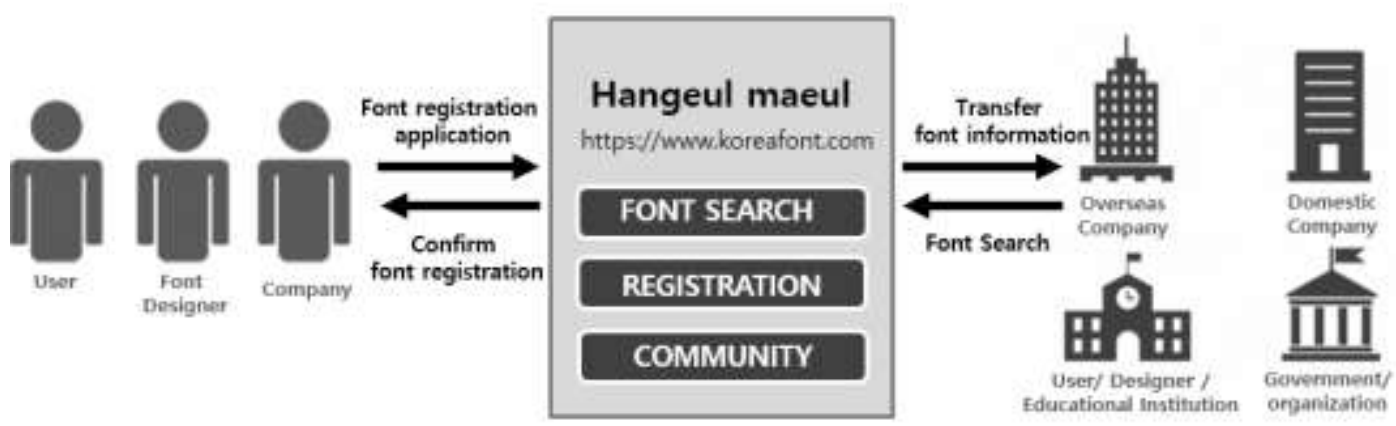

Figure 2. Use of 'Hangeul maeul'

\subsection{Registration Process}

'Hangeul maeul' allows font makers, font designers, general people and students to access the font registration site and allow them to apply for their own fonts. The submitted fonts can be registered and confirmed by checking the similarity of the registration system 
and verification of commercialization. The similarity verification is protecting the copyright of the font design by preventing the registration of indiscriminate fonts and checking the similarity of the design. Furthermore, the registered fonts are directly retrieved and used as a database for similarity examination. Commercialization verification is checking the factors that may occur when applying the registered fonts to OS, editing software, devices, etc., in advance. If there is a modification, it is requested to modify the contents and re-register.

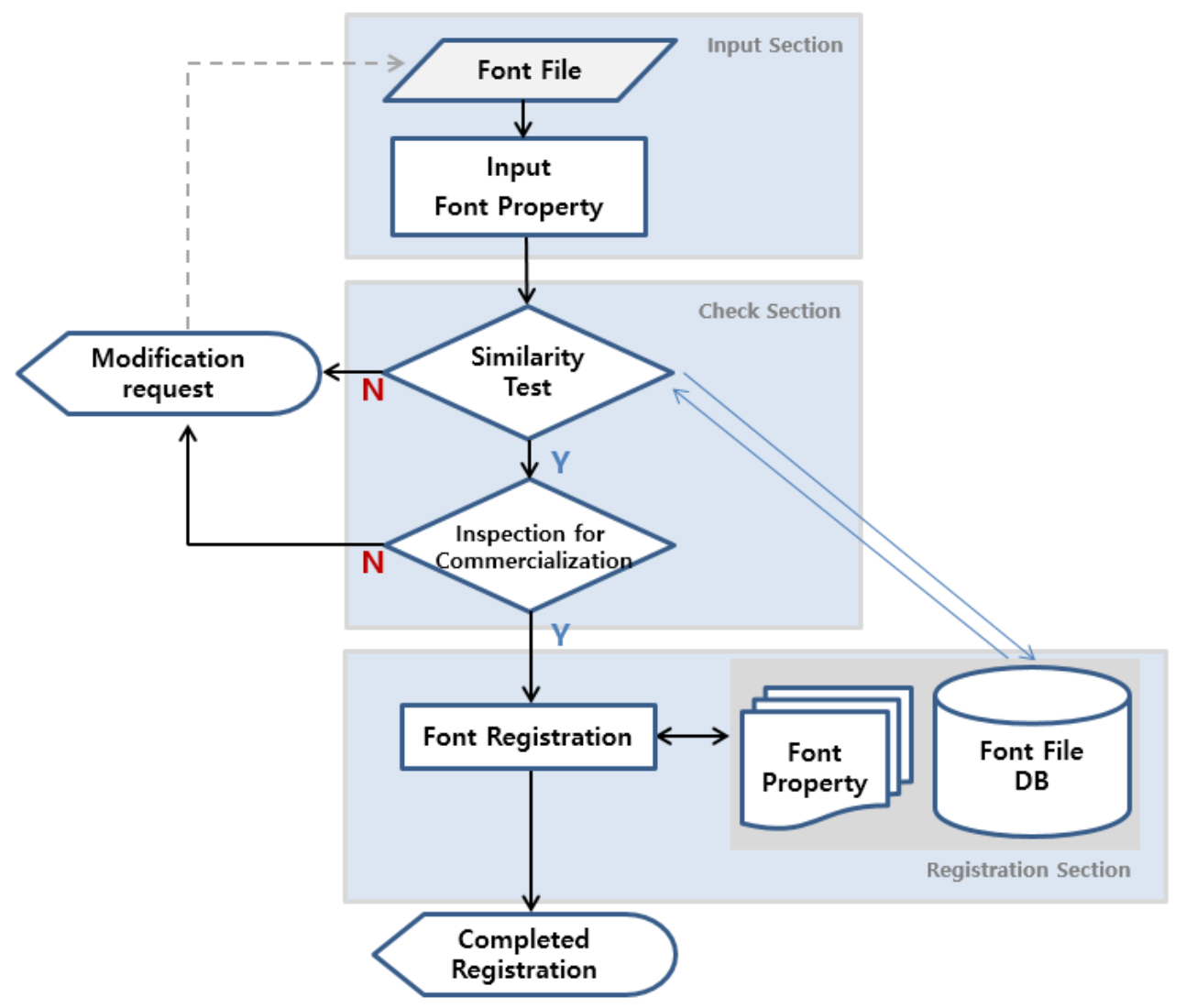

Figure 3. Registration Process of 'Hangeul maeul'

In addition to the visual classification according to the Telecommunications Technology Association (TTA) standard, the classification of the intuitive user feeling about the font thickness are added. Moreover, through the font license selection and information input of specification, it is possible to search by considering the use purpose of the font and the necessary code set. Table 2 shows font property classification table required when registering. The registered fonts can be checked with the detailed information on the My Page menu, and the attributes can be modified.

Table 2. Font Property Classification Table Required when Registering

\begin{tabular}{|c|c|c|}
\hline Font Property & Classification & Explanation \\
\hline \multirow{2}{*}{ design } & \multicolumn{2}{|c|}{ TTAK.KO-10.0906-Part2 (Refer to Table 1) } \\
\hline \multirow{2}{*}{ Thickness } & Thin & \multirow{2}{*}{$\begin{array}{c}\text { Classification of the most intuitive thicknesses the } \\
\text { user feels. }\end{array}$} \\
\cline { 2 - 2 } & Thick & $\begin{array}{c}\text { Refers to a paid font designed for use in general } \\
\text { documents, web pages, brochures, catalogs, and }\end{array}$ \\
\cline { 2 - 3 } cost & Pckage &
\end{tabular}




\begin{tabular}{|c|c|c|}
\hline & & printed materials. \\
\hline & Mobile & $\begin{array}{c}\text { Fonts that is sold for a fee in the mobile download } \\
\text { service system. Fonts tailored to the mobile } \\
\text { environment. }\end{array}$ \\
\hline & public & $\begin{array}{l}\text { Open font, free of charge, without any restrictions. } \\
\text { Fonts in this category are user-customizable, and } \\
\text { are available for distribution and commercial use. }\end{array}$ \\
\hline & Free & $\begin{array}{c}\text { Font that is used for non-commercial purposes or } \\
\text { is distributed for free use by restricting the } \\
\text { environment used by the font maker and the } \\
\text { manufacturer. }\end{array}$ \\
\hline \multirow{7}{*}{ Spec. } & Hangeul & $\begin{array}{c}\text { Basic 2,350/ Extension 11,172/ Hangeul Syllables/ } \\
\text { etc(Ancient language) }\end{array}$ \\
\hline & Chinese character & $\begin{array}{c}\text { Basic 4,888/ CJK / Extension 7,500/ GB2312/ } \\
\text { Big5 / S-Jis }\end{array}$ \\
\hline & Alphabet & Basic Latin/ Latin -1/ Latin Extended_A \\
\hline & Numbers \& Digits & $\begin{array}{c}\text { Circled Digits / Parenthesized Digits/ Roman } \\
\text { numerals/ etc }\end{array}$ \\
\hline & Symbols & $\begin{array}{l}\text { Punctuation/ Mathematical Symbols / Geometric } \\
\text { Shapes / unit symbol / rule mark / fraction }\end{array}$ \\
\hline & Foreign language & Greek/ Latin / Ghana / Cyrillic \\
\hline & Etc. & Support characters can be entered directly. \\
\hline
\end{tabular}

\subsection{Search Process}

The search for fonts is based on the attributes entered during registration. Design classification, Usage classification, Thickness classification, Company (Author) classification, and Keyword search are provided. For the search result, the font name and the example text of the font are displayed to provide the user with a preview function. The order of search results is supported by name, order of view, and registration order.
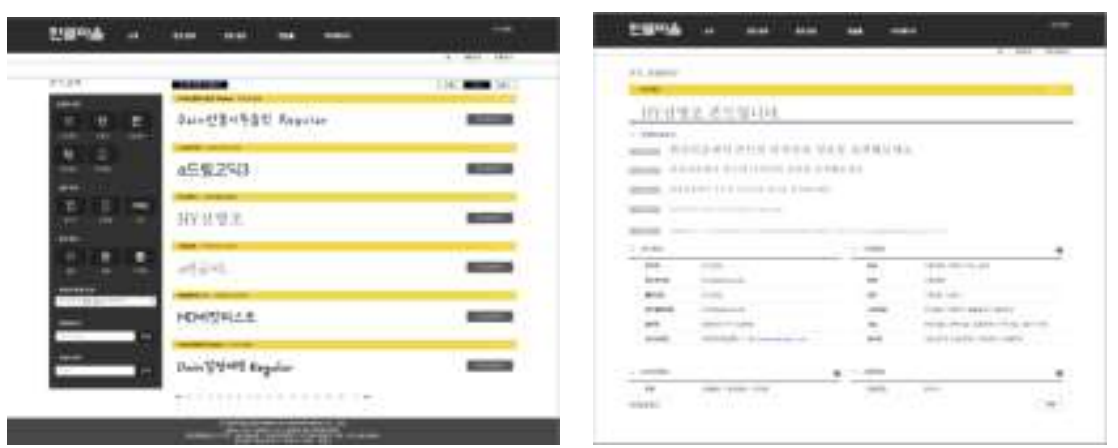

Figure 4. Example of Search and Registration Page on 'Hangeul maeul'

The design classification is inputted when registering the font requires from the small classification defined by the standard, but the search only supports the large classification. This will be supported for further inquiry, in fact, however, for non-experts it may be a meaningless classification without knowledge of the detailed classification.

Furthermore, the feeling of the font can be felt differently depending on the letter to be expressed. Even if it is a preferred font, it may not fit well to the part that you are going to use. This problem is very important because the design field is really sensitive. Therefore, it is very useful to check and select the font impression for each phrase you use, and 'Hangeul maeul' supports this. The 'Sentence writing' is a function for checking and selecting the font impression for each phrase you use, and an example of this is shown in Figure 5 . 


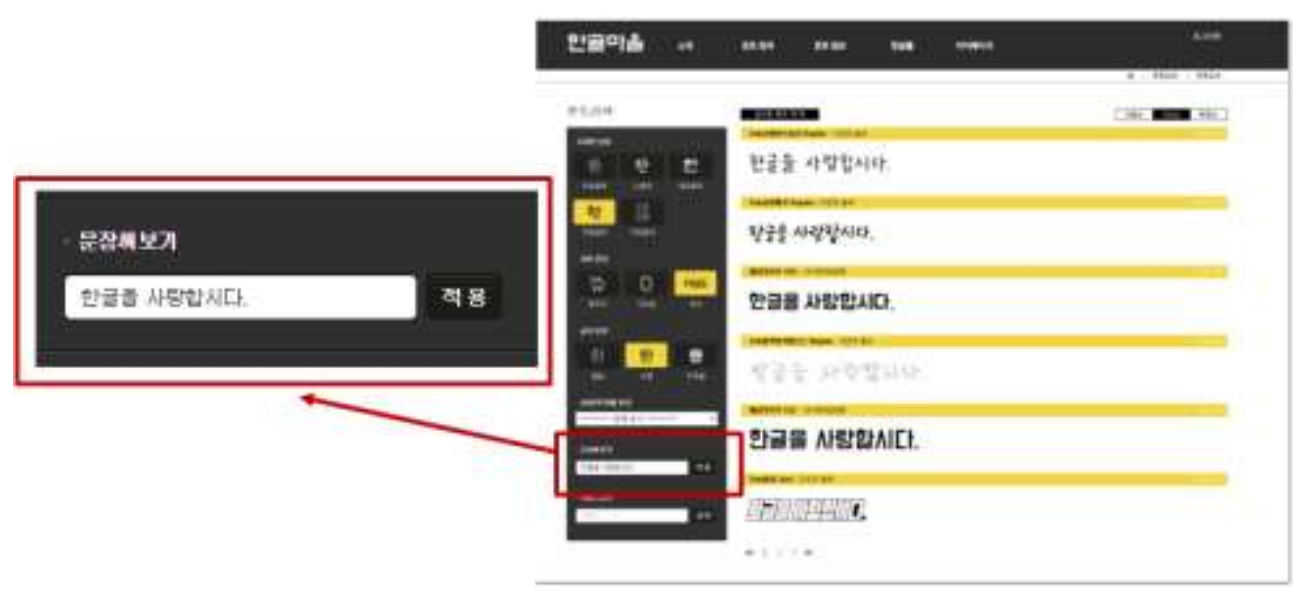

Figure 5. Example of Font Preview by Sentence on 'Hangeul maeul'

\section{Usability Test}

Although the system is highly needed, if usability is not good, it will be ignored by users. Usability test is not done at once, but is needed for iterative improvement. This chapter contains the design of how to evaluate the usability of 'Hangeul maeul' and the analysis results for future improvement.

\subsection{Design User Evaluation}

In order to evaluate the usability, the user should select the main task to perform through the system and observe the user in performing each task[10,11,12]. Table 3 shows the task hierarchical structure for user evaluation. In Task 3, Task 4, and Task 5, the user is asked to select the font of the preferred style and then the search function is used to find a satisfactory font. In Task 6, the image of the specific font is displayed first, and performs to find the name of the font through attribute classification.

The task hierarchical structure can grasp the top and bottom task list for each task at a glance, but it has a disadvantage that it is difficult to grasp the movement line in which the user practically performs tasks. Therefore, a work flow task diagram was constructed in order to recognize the optimal movement of the user in using 'Hangeul maeul' system, and it was tested by comparing with the execution process of the participants. Experiments for usability test were classified into two groups according to the experience of font design: general users and font designers.

\section{Table 3. Task Hierarchical Structure}

\begin{tabular}{|l|l|l|}
\hline \multicolumn{1}{|c|}{ Task Class } & \multicolumn{1}{|c|}{ Task Name } & \multicolumn{1}{c|}{ Task Descriptions } \\
\hline $\begin{array}{l}\text { Registering } \\
\text { fonts }\end{array}$ & [Task 1 ] Registering fonts & $\begin{array}{l}\text { Joining 'Hangeul maeul'. } \\
\text { Uploading font files. } \\
\text { Specifying font properties. }\end{array}$ \\
\cline { 2 - 3 } & $\begin{array}{l}\text { [Task 2] Modifying font } \\
\text { registration information }\end{array}$ & $\begin{array}{l}\text { Checking registered fonts. } \\
\text { Modifying font properties. } \\
\text { Checking font property modification. }\end{array}$ \\
\hline $\begin{array}{l}\text { Searching } \\
\text { fonts }\end{array}$ & $\begin{array}{l}\text { [Task 3] Searching fonts by } \\
\text { using font attributes }\end{array}$ & $\begin{array}{l}\text { Specifying search attributes. } \\
\text { Checking font details. }\end{array}$ \\
\cline { 2 - 3 } & $\begin{array}{l}\text { [Task 4] Searching fonts with } \\
\text { high view rank }\end{array}$ & $\begin{array}{l}\text { Searching by order of sorted views. } \\
\text { Checking font details. }\end{array}$ \\
\hline
\end{tabular}




\begin{tabular}{|l|l|l|}
\hline & $\begin{array}{l}\text { [Task 5] Searching optimal } \\
\text { fonts by sentence }\end{array}$ & $\begin{array}{l}\text { Applying the input of the sentence to use. } \\
\text { Checking font details. }\end{array}$ \\
\cline { 2 - 3 } & $\begin{array}{l}\text { [Task 6] Searching optimal } \\
\text { fonts by sentence }\end{array}$ & $\begin{array}{l}\text { Understanding attributes of the fonts presented. } \\
\text { Specifying search attributes. } \\
\text { Checking font details. }\end{array}$ \\
\hline
\end{tabular}

Table 4 shows the results of the group satisfaction survey conducted on the subjects after the usability test and was evaluated on a 5 points scale.

\section{Table 4. Survey Contents Related to User Satisfaction of Each Group}

\begin{tabular}{|c|c|c|}
$\begin{array}{c}\text { Survey } \\
\text { number for } \\
\text { font } \\
\text { designers }\end{array}$ & $\begin{array}{c}\text { Survey } \\
\text { number for } \\
\text { general } \\
\text { users }\end{array}$ & Survey Contents \\
\hline 1 & 1 & Was it easy to accomplish the task as a whole? \\
\hline 2 & 2 & $\begin{array}{l}\text { In terms of font designers, do you think ' Hangeul maeul ' system is } \\
\text { useful for using of Korean fonts? }\end{array}$ \\
\hline 3 & 3 & $\begin{array}{l}\text { Do you think ' Hangeul maeul ' system is useful to use Hangeul } \\
\text { font? }\end{array}$ \\
\hline 4 & 4 & $\begin{array}{l}\text { Wo you think the site and system are well reflected which related to } \\
\text { your prediction before clicking a menu or button? } \\
\text { Are step-by-step instructions adequately provided? }\end{array}$ \\
\hline 6 & 5 & $\begin{array}{l}\text { Was it useful to search for a specific font (recognizing the shape of } \\
\text { the font)? } \\
\text { Was it useful to search for the font you wanted? }\end{array}$ \\
\hline 7 & 6 &
\end{tabular}

With the conduction of user satisfaction survey, survey on error severity was also made. The error items consisted of representative errors that were either derived from the pilot test or considered likely to be derived.

Table 5 is a survey to test the error severity. 5 points scale.

Table 5. Survey for Testing the Severity of the Error

\begin{tabular}{|l|l|c|}
\hline & \multicolumn{1}{|c|}{ Error related survey } & Error Attributes \\
\hline 1 & Difficult to understand menu names and functions. & Behavior-inducing \\
\hline 2 & System speed or error is triggered. & Reaction of system \\
3 & Hard to find a function. & Visual clarity \\
\hline 4 & Lack of description of font related terms. & User convenience \\
\hline
\end{tabular}

In addition to that at the time of interview, interviewers were recorded about the inconveniences pointed out by the subjects of evaluation. In accordance with the various inconveniences, we classified them into four error attributes (user convenience, visual clarity, behavioral induction, system response).

\subsection{Usability Test Analysis}

Figure 6 shows the success rate of participant task by group. Both groups participants were successfully accomplishing the task. The overall difference between general users and font designers seems to be due to the cognitive abilities of the font-related terms used in font classification. In particular, task 6 , which looks at the font of the presented font 
and finds the font name, shows a wider gap in understanding the visual classification terms as absolute.

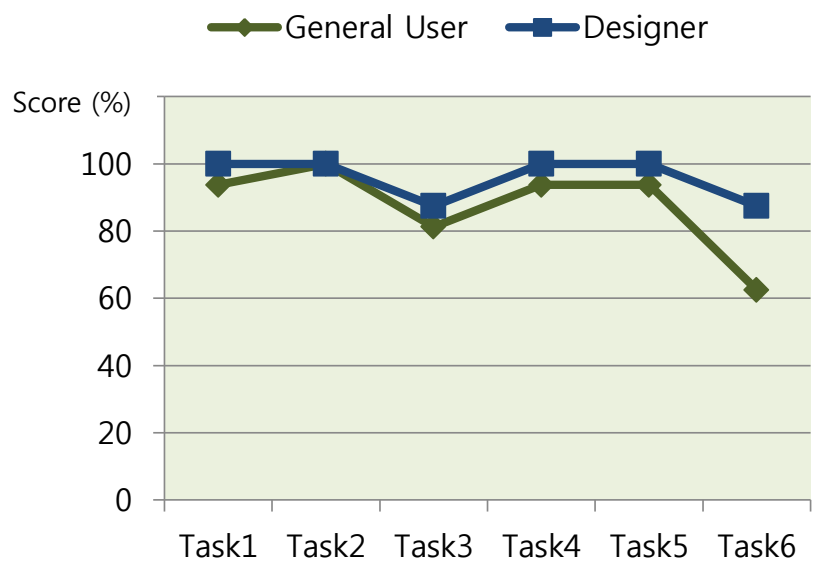

\begin{tabular}{|c|c|c|}
\hline \multicolumn{2}{|c|}{ Success/Failure } & $\begin{array}{c}\text { Score } \\
(\%)\end{array}$ \\
\hline Full success & S & 100 \\
\hline \multirow{2}{*}{ Partial success } & P1 & 75 \\
\cline { 2 - 3 } & P2 & 50 \\
\hline Failure & F & 0 \\
\hline Exception & E & except \\
\hline
\end{tabular}

Figure 6. Success Rate per Task

Figure 7 shows an analysis of the number of unnecessary processes checked (the number of times the observer checked the situation quantitatively in terms of clicks and scrolls) and the number of time-lag occurrences (checked by task and related behavior every 30 seconds). It is not a fatal error or a mistake to say that the task is not successful, but the indicator of usability is called performance noise which is meaningful.

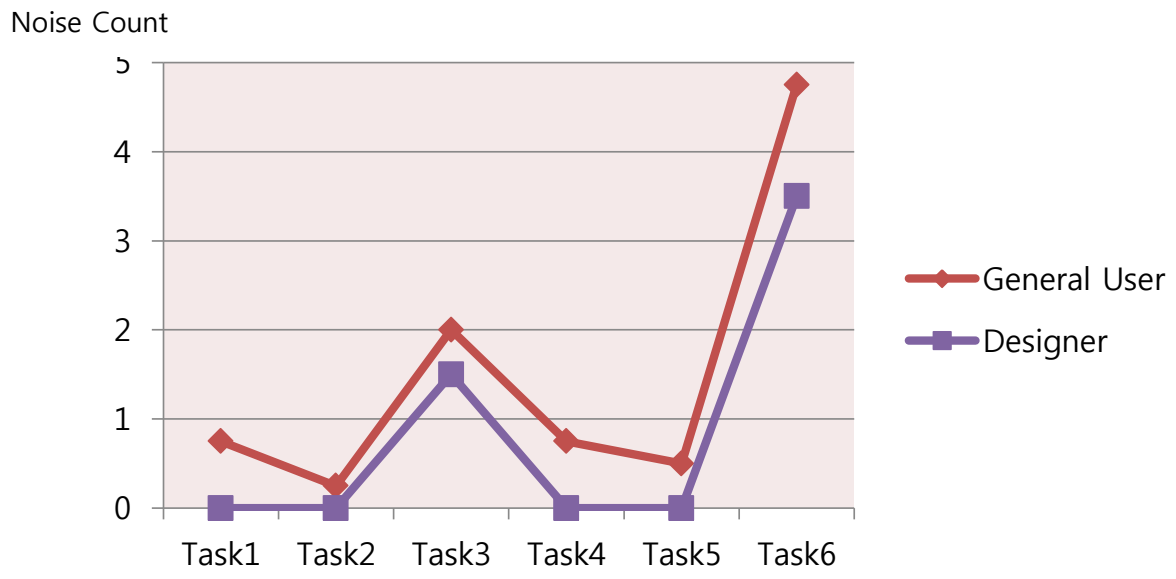

Figure 7. Amount of Noise Generated per Task

General users' noise frequency of the task was also higher than font designers. In the case of 'Task 1', there was a case where noise occurred due to existence of the registration menu places at the bottom. In selecting the classification in the registration procedure, a question about whether it is mandatory. In addition, hesitation can be occurring. As shown in the task success rate, most of the noise generated in tasks 3 and 8 were attributed to the recognition of the font classification. Especially, in the case of Task 6, which looks at the shape of the font and determines the classification attribute, all of the participants succeeded but succeeded after a lot of trial and error. 


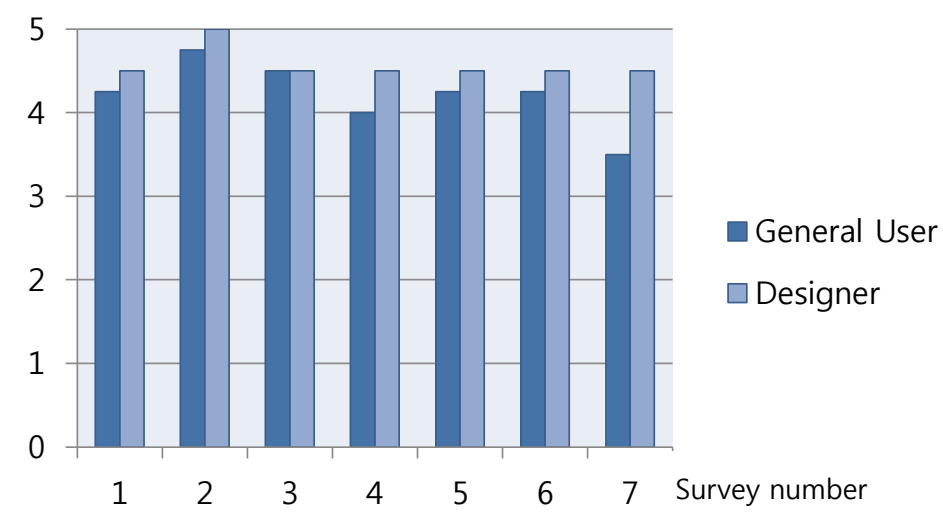

Figure 8. User Satisfaction of the Testing Group

Figure 8 shows the results of each group satisfaction survey. Though there were some problems that showed relatively low success rate and high noise generation rate, they were mostly shows high satisfaction of the system. Except for the unfamiliar font classification term problem, it was judged that there was no problem in registering and searching the font of the user, and evaluated utilization value highly.

Figure 9 shows the error severity level for the error item. Even though people did not evaluate the error items as serious, more than half of the evaluation participants interviewed that improvement of font classification needed to improve the efficiency of search.

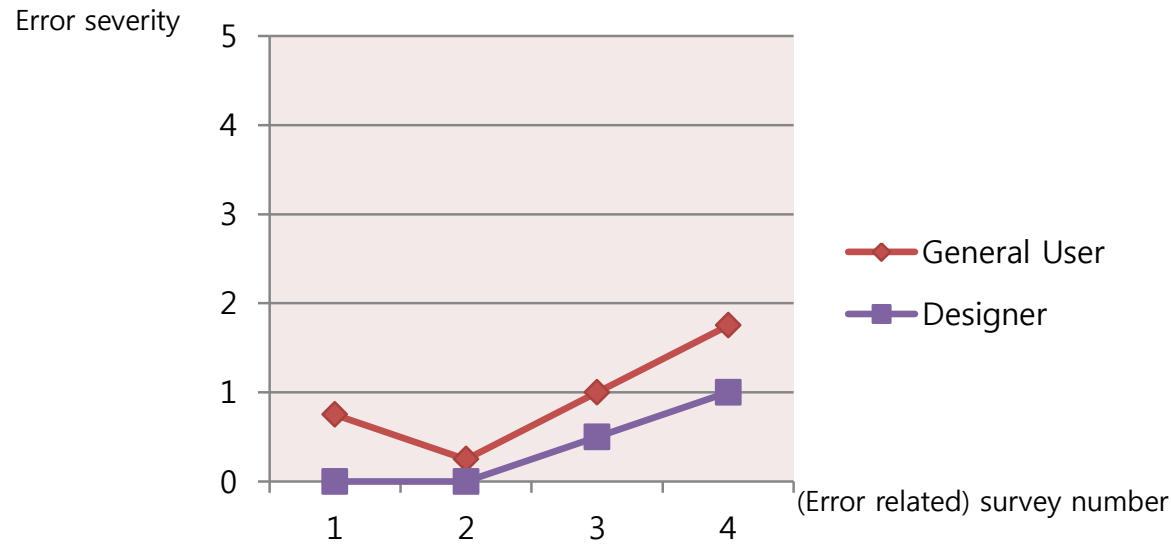

Figure 9. Severity Level for Error Entries

In the interview after the user evaluation, the complaints described by the evaluation participants were classified according to the four error attributes. The results are shown in Figure 10. 


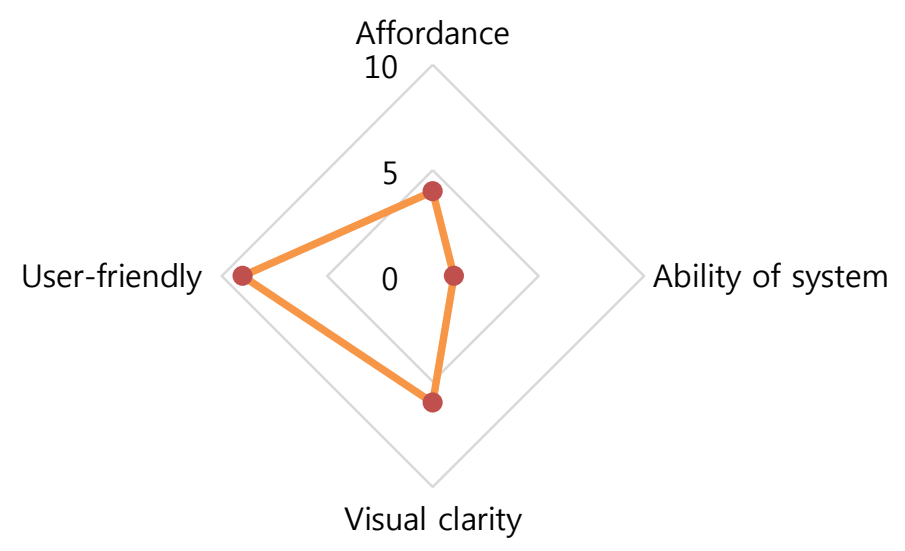

Figure 10. Number of Inconveniences per Error Property

The error attribute that generated the most inconveniences was user-friendliness. Despite the high task performance and satisfaction, the noise generated by the lack of ancillary explanation or high-cognitive intelligence interface design, in the user's use of the system. Therefore, if a term description for the font classification, a detailed search function addition, and a more improved interface are provided, it can be utilized as a more effective Korean font registration system in the future.

\section{Conclusion}

It can be seen by the Korean illiteracy rate, which is close to zero, and this rate definitely shows that Hangeul means of absolute communication for Koreans. Communication through Hangeul has recently been able to transmit richer expressions and emotions due to various font developments, and the Hangeul font industry has expanded accordingly. However, compared to the expanded Hangeul font industry, there is not enough effort to integrate and utilize information about Hangeul fonts. Making the existing fonts into a DB will play a very important role in the future development of the font industry, it will allow to make it easier to search for fonts, and it will also enable manufacturers and font designers to register and share their own fonts.

Therefore, we developed ' Hangeul maeul ', the first case of Korean font registration system in Korea. The recent standard visual classification's standard, license, and specification information of Korean font are added, and creating DB about the detailed information about the font. Moreover, in order to protect the copyright of the original font design and indiscreet registration, similarity check and font commercialization verification were developed and added to the registration process to build a more effective registration system.' Hangeul maeul' provides registration of Korean font information and font information retrieval and confirmed its effectiveness through usability test. As a result of the usability test, supplementary description of visual classification system and more detailed retrieval of the Korean font classification system were required, but generally, high satisfaction and success rate of use were obtained. Improvements obtained from usability evaluation will be accommodated in the later development process and will be developed into a more effective Hangeul font registration system.

\section{Acknowledgments}

This research was supported by Culture Technology Research and Development Program through the Korea Creative Content Agency funded by the Ministry of Culture, Sports and Tourism, Korea. 


\section{References}

[1] ADOBE Typekit site, "https://typekit.com/fonts?collection=foundry-adobe", Accessed on September $10,(2016)$

[2] P. O'Donovan, J. Libeks, A. Agarwala, A. Hertzmann, "Exploratory font selection using crowdsourced attributes", ACM Transactions on Graphics, Volume 33 Issue 4, Article No. 92, (2014), pp 1-9

[3] Hangeul Maeul, http://koreafont.com, Accessed May 10, (2016)

[4] PG608 e-Publishing Working Group, "Hangeul Font Production Guides For Font Registration System Part 2. Design based Classification," TTA, TTAK.KO-10.0906- Part2. (2016)

[5] ISO/IEC JTC 1/SC 34, "ISO/IEC 9541-1:2012 Information technology -- Font information interchange - Annex A Typeface design grouping", The International Organization for Standardization (2012)

[6] H.Y. Kim, S.B. Lim, "Hangeul Font Classification Study based on Numerical Analysis", Extended Abstracts of HCI Korea 2016, (2016), pp 180-181.

[7] Eunjoo Sin, Dasom Lee, Soo-Yeon Lee, Soon-Bum Lim, "Solution to Problem of Constant Cluster When Chinese Is Notated by Using Hangeul Input Keyboard Based on Hunminjeongeum", The 4th Workshop on Ubiquitous Science and Engineering, Jeju, (2016) april 19 -21

[8] Mi Hwa Moon, Dong Ryun Chang, "The Research on Typeface Impression Depending on Change Of Design Factors", Bulletin of Korean Society of Basic Design \& Art, vol. 16, no. 4, (2015), pp.191-202

[9] H.Y.Kim, Y.H.Park, S.B.Lim, "Hangeul Property Study for Font Matching and Recommendation System", The 12th International Conference on Multimedia Information Technology and Applications, Luang Prabang, Laos, (2016) July 4-6

[10] Steve Krug, "Rocket surgery made easy : the do-it-yourself guide to finding and fix", New Riders, (2009)

[11] Jakob Nielsen, "Prioritizing Web Usability", New Riders, (2006)

[12] Thomas Tullis, William Albert, "Measuring the User Experience: Collecting, Analyzing, and Presenting Usability Metrics (Interactive Technologies)”, Morgan Kaufmann, (2008)

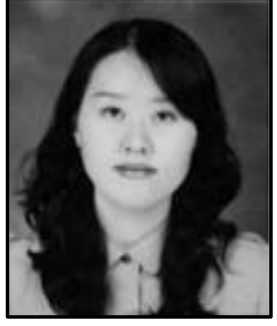

Eun-joo Sin, received her BS degree from Sookmyung Women's University, Korea, in 2000 and her MS degrees in information science from Ewha Womans University, Korea, in 2004. Her Ph.D degrees in computer science from Sookmyung Women's University, Korea, in 2010. From 2011 to 2016, he was an teaching professor in the Dept. of IT Engineering at Sookmyung Women's University in Korea. From 2017, she is currently a senior researcher in Research Institute of ICT Convergence at Sookmyung Women's University in Korea. Her main research interests are web technology, user interface, usability testing, human sensibility, and Digital Media literacy.

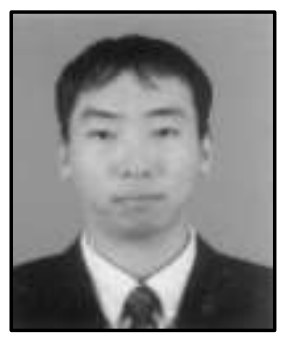

Ki-Deok Park, received his BS degree from Chung-Ang University, Korea, in 2003. From 2004, he is currently a general manager in the Dept. of Mobile Communication R\&D Center at HanYang Information \& Communications Co., Ltd. in Korea. His main research interests are web and mobile fonts, computer graphics, and machine-learning.

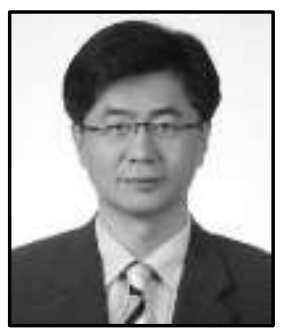

Soon-Bum Lim, received his BS degree from Seoul National University, Korea, in 1982 and his MS and Ph.D degrees in computer science from KAIST (Korea Advanced Institute of Science and Technology), Korea, in 1983 and 1992, respectively. From 1989 to 1997, he was the engineering director for the font technology and printer division at Human Computer, Inc, and 
Trigem Computer, Inc. From 1997, he was an assistant professor in the Dept. of Computer Science at Konkuk University in Korea. From 2001, he is currently a professor in the Dept. of IT Engineering at Sookmyung Women's University in Korea. His main research interests are computer graphics, web and mobile multimedia contents, user interface, and electronic publishing such as font, eBook, and XML documents. 